\title{
Picture Guided Learning - a Picture-Based Clinical Skill Teaching Resource in Undergraduate Nursing in South Australia
}

\author{
Ying Yu ${ }^{1}$, Jodie Price ${ }^{1}$, Vincent Pearson ${ }^{1}$, Leeanne Pront ${ }^{1}$, Angie Sterland ${ }^{1}$, Maurine Redden ${ }^{1}$, \\ Fathimath Shifaza ${ }^{1}$ \\ ${ }^{1}$ College of Nursing and Health Sciences, Flinders University, South Australia \\ Corresponding author: Ying Yu (e-mail: ying.yu@ flinders.edu.au).
}

Acknowledgment: We thank Dr Pauline Hill and Lucie Steber for their valuable feedback during the CSS development. We also thank all staff in the Simulation Hub for their help in printing and implementing the CSS.

\begin{abstract}
A competent nursing graduate is required to perform psychomotor skills related to clinical procedures, articulate knowledge to support their activities, work in a team with efficient time management skills and have strategies to perform in the increasingly busy clinical environment and with complex patient acuity. Student Evaluation of Teaching data from an undergraduate nursing clinical subject 2014-2018 identified an inconsistency in clinical skill teaching/delivery by educators which needed to be addressed. This study aimed to evaluate the outcome of implementing the Clinical Skill Storybook as an additional teaching resource for students' clinical skill development. A descriptive analysis approach was applied to summarise quantitative and qualitative subject evaluation data along with Clinical Skill Storybook evaluation questionnaires (20182020). Data analysis identified five themes: (1) Clinical Skill Storybook as a Learning Resource, (2) Selfdirected learning and peer support, (3) Developing clinical skill competency, (4) Preparation for clinical placement, and (5) Maintaining teaching consistency. The subject evaluation highlights that student were significantly more satisfied with the teaching resources than in previous years. The implementation of the Clinical Skill Storybook actively improved students' skill acquisition, confidence, and readiness for placement. The findings indicate that the Clinical Skill Storybook is beneficial for nursing students' clinical skill development, subsequently beneficial to institutions due to improved students' performance and satisfaction. Further involvement with stakeholders such as clinical venues in developing the clinical skill storybook is planned for future exploration.
\end{abstract}

INDEX TERMS: Clinical Skill Storybook, Clinical Skill Teaching, Undergraduate Nursing, Nursing Skills, Psychomotor Skills, Skills laboratory, Clinical competence.

\section{INTRODUCTION}

Nurse education requires the combination of both theory and practice; the integration of these components necessitates the involvement of effective psychomotor and cognitive skills. Developing nursing students' clinical skills competency is a key focus in many undergraduate nursing programs. Nurse Educators are continually seeking methods to assist students to develop and perform clinical skills accurately, consistently and in a confident and proficient manner. Despite the effort, the newly graduated nurse is often clinically challenged, lacks confidence and perceived as incompetent in performing clinical skills [1,2].

Clinical skill laboratories are simulated environments that enable students to develop psychomotor skills [3]. Historically, students have been exposed to a range of practice modalities to establish how a clinician undertakes clinical skills. The 'traditional' method for teaching clinical skills involved a demonstration of the skill by an educator to groups of 25-30 students, followed by an opportunity to practice under supervision. However, this is becoming increasingly 
difficult, due to the increased size of student cohorts, a broader teaching team with limited resources and issues of patient safety to consider.

Students should be able to practice clinical skills in a safe environment with immediate feedback on their performance, prior to undertaking clinical placement as successful learning requires a feeling of security [4]. However, having a large student cohort challenges the consistency of teaching within the skills laboratory, resulting in differing student experiences and additional demands on consumables and resources. It also highlights the variances in practices of educators. The requirements for a larger number of teaching staff leads to concerns about procedural inconsistencies. Also, researchers agree that teaching inconsistency leads to student confusion, stress and impedes mastery of skills [5].

A variety of technology-based, clinical skills teaching materials are available to improve the teaching consistency however, not all comply with Evidence-Based Practice standards and result in confusion for both educators and students. While many studies report innovation related to clinical skills such as using mobile application or computerized instructions [6, 7], pictorial instructions are commonplace in health settings and are often displayed strategically in venues as prompts for clinicians when undertaking clinical skills and procedures that are less common and infrequently practiced $[8,9]$. Teaching strategies that include the use of pictorials allows the educator to tailor teaching and reassess comprehension until the information has been mastered. Importantly, pictures, when added to written and verbal information, appear to be helpful [8-10]. Ensuring a high level of competency in clinical skills acquisition may reduce healthcare costs and increase patient safety [11]. However, the educational benefit of using pictorial instructions in a skills laboratory is considered a research gap. No published studies on the topic of pictorial clinical skills were found. Therefore, this study sought to determine the intervention effect of pictorial instructions "Clinical Skill Storybook" in the clinical skill laboratory of an undergraduate nursing program.

This study aimed to evaluate the outcome of implementing the Clinical Skill Storybook as an additional teaching resource for undergraduate nursing students' clinical skill development.

\section{METHOD}

\section{A. STUDY DESIGN AND SETTING}

A quality improvement project was undertaken between 2018-2020 to teach clinical skills in the nursing laboratories for second-year nursing students attending a university in South Australia (SA).

\section{B. ETHICAL CONSIDERATIONS}

Written permission and approval were obtained from the Social and Behavioral Research Ethics Committee (Project
No.8207). This enabled evaluation of the Clinical Skills Storybook via questionnaire exploring the benefit of this resource for clinical skills learning and teaching.

\section{STUDY INSTRUMENT}

Clinical Skill Storybook (CSS) is a sequential pictorial booklet that provides a clear "picture" of complex clinical skills in a simplified manner. The aim is to enhance students' development of motor skills methodically and systematically. Development of the CSS was informed by Vygotsky's Zone of Proximal Development [12] and thus, was constructed in a manner for students to be able to master a skill through making an informed choice about what they already knew and where they required further guidance or support. Further to this, the CSS provides a consistent, practice-relevant evidenced-based reference for the context in which students will undertake their clinical placement. The CSS has been developed according to best-practice evidence compliant with SA Health policy and procedure guidelines. Clinical skills were photographed step by step in the College simulation hub using an author's mobile phone. All photos were then uploaded to a computer and collated using Microsoft Publisher ${ }^{\circledR}$. The final product was peerreviewed by clinicians in the practice before printed and displayed for use. The entire process was completed in the college using existing resources at minimal cost. An example is presented in FIGURE 1.

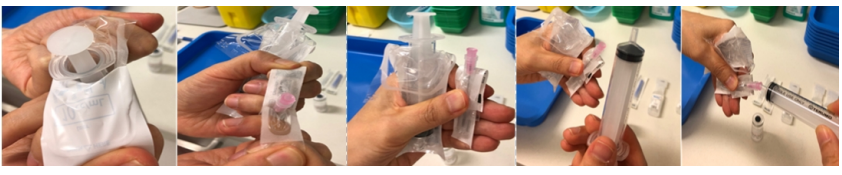

FIGURE 1. Example of Clinical Skill Storybook

\section{IMPLEMENTATION OF THE STUDY}

The CSS was implemented in a second-year clinical subject that integrates theory and practice in both acute and community healthcare settings. The subject included eight weeks of tutorials and clinical laboratory sessions followed by 160 hours of professional clinical placement. Prior to the scheduled clinical laboratory session, students were asked to read the subject materials, including textbook readings and self-directed CSS review.

\section{E. DATA SOURCES}

Data was collected from two sources; 1) using an open-ended Qualtrics survey (Clinical Skill Storybook evaluation questionnaires) developed by the principal investigator; 2) Student Evaluation Teaching (SET) a university student feedback process for all subjects completed by students at the end of the subject also provided data.

Clinical Skill Storybook evaluation questionnaires: Openended questions were used to explore the effectiveness of CSS. 
SET: SET survey was used in conjunction with the CSS online questionnaire to explore the benefits of this teaching resource for clinical skills learning and teaching. Students and educators were informed that their participation in the evaluation process was voluntary. They were also aware that their decision on participation in the evaluation of the CSS would not affect their final grades or performance review for the nursing program.

\section{F. DATA ANALYSIS}

\section{1.) QUANTITATIVE}

Quantitative data (demographic data, students satisfaction rate from SET) were entered into the SPSS statistical software, Version 22.0 (SPSS Inc, Chicago, IL). Descriptive statistics inform the participants' demographic information.

\section{2.) QUALITATIVE DATA}

Free-text comments and open-ended responses from both questionnaires were extracted and entered into an Excel spreadsheet. Analysis of the free-text comments was conducted using thematic analysis [13], with initial analysis informing emerging themes. The emergent themes were then used to provide coding categories for a more in-depth analysis. Coding of all comments into themes was undertaken independently by two researchers (Y.Y. and F.S.), and any discrepancies in key themes were resolved by discussion. The final analysis revealed five consistent themes.

\section{RESULT}

Of 2172 students enrolled in second-year between 2018 and $2020,53 \%$ were international students, $83 \%$ of students were female, and most students were aged between 20-39 years. The student's demographics are presented in FIGURE 2(a) and FIGURE 2(b). Among all enrolled students, a total of 315 students completed the SET and 254 students completed CSS evaluation questionnaires. It is unclear if the same students completed both data points.

\section{A. QUALITATIVE RESULTS}

Five key themes emerged from the open responses:

(1) CSS as a Learning Resource,

(2) Self-directed learning and peer support,

(3) Developing clinical skill competency,

(4) Preparation for clinical placement, and

(5) Maintaining teaching consistency.

\section{1) CSS AS A LEARNING RESOURCE}

Students were overwhelmingly positive in evaluating the CSS as a helpful learning resource. Students expressed satisfaction with the CSS, stating that it allowed them to use it as a reference providing clear instructions in a step-by-step process. One student wrote, "clinical skill storybook was helpful because it is clear and easy to comprehend" (Student 2, 2018) while another student stated "it shows me the way to do it and the rationale" (Student 9, 2019).

Students believed the CSS provided an easy-to-follow visual guide which assisted development of their confidence and competency in performing clinical skills. The key terms students used to describe the CSS included but were not limited to "clear", "easy", "visual", and "prepare".

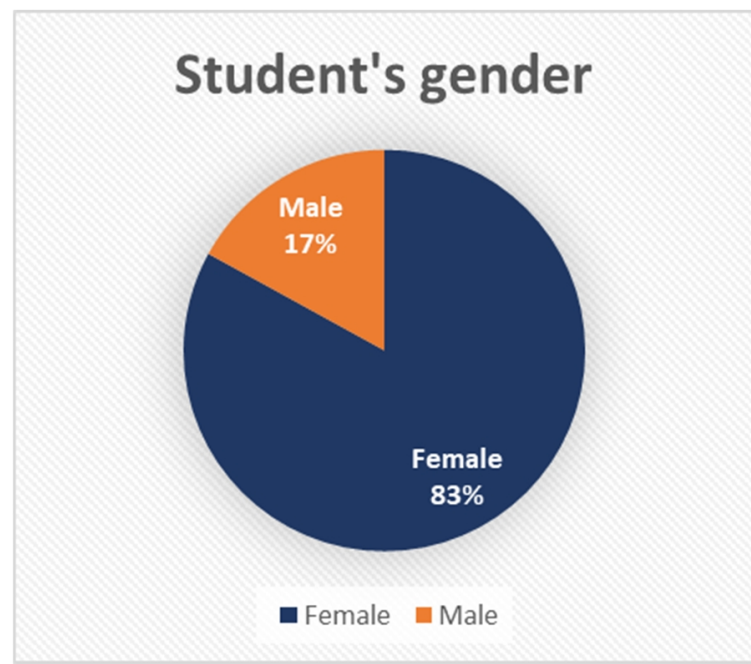

(a)

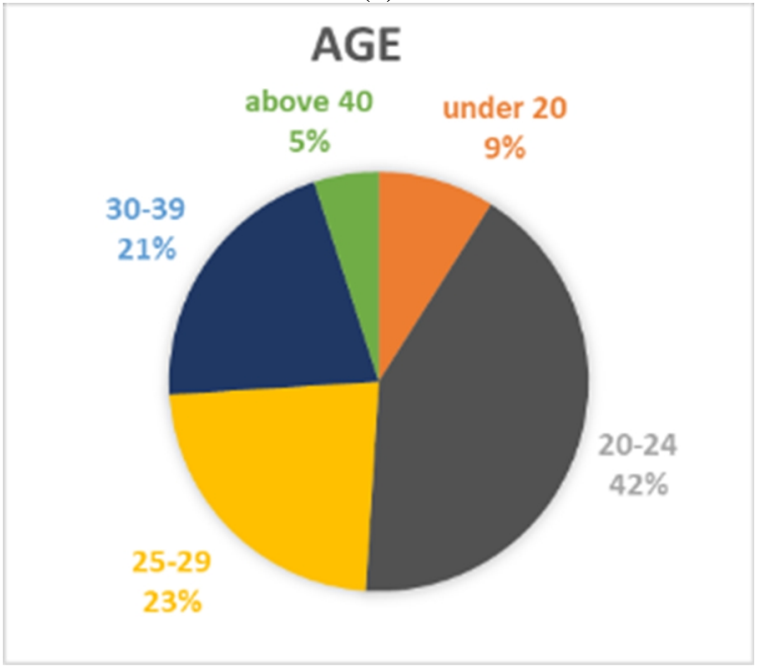

(b)

FIGURE 2. Student's demographics a) gender, and b) age

\section{2) SELF-DIRECTED LEARNING AND PEER SUPPORT}

A consequential outcome from the CSS was the promotion of self-directed and peer-supported learning. Students identified the CSS was very useful for visualising skills and the step-by-step process helped them to understand complex skills that they may not have otherwise understood. 
"We used clinical skill storybook which helped us to perform the skill step by step" (Student 7, 2020).

This was particularly important for students who identified as visual learners:

"Helps with visual learners. Super helpful for when you are stuck on a step on the procedure" (Student 17, 2020).

Many participants commented that the details of the pictures made it easy for them to follow. Significantly it emerged that students in this subject believed that they had an opportunity to promote their clinical skills and knowledge acquisition as the CSS provided the greatest learning.

\section{3). DEVELOPING CLINICAL SKILL COMPETENCY}

Gaining competence and confidence in practical nursing skills is an integral part of the nurses' professional practice. Students explicitly stated that the CSS helped develop clinical skill competency and prepared them for clinical placement.

"This (CSS) has helped us to understand complex skills that we may not have otherwise understood. It has allowed me to think of 'why' scenarios may happen and place theory into practice" (Student 16, 2020).

The positive attitudes from the students towards clinical skill development occurred from their willingness to use the innovative CSS to facilitate their learning. Many students requested to use it in their other clinical subjects and placement. One student even asked if she could use it after graduation. Students' evaluation of the CSS indicated that most participants used the CSS more than once.

\section{4) PREPARATION FOR CLINICAL PLACEMENT}

Enhancing clinical preparation was one of the educational objectives of the CSS. In seeking to prepare students for the realities of practice, the CSS was seen as an important element to support students' readiness for clinical placement. The greatest number of participants commented upon the helpfulness of the CSS to support their preparation for clinical placement. One participant commented,

"prepares for placement as a student can take notes on practice also saves on time, studying storybook prior and reading at labs allow students to practice" (Student 44, 2020).

Many students commented that the CSS provided an opportunity for them to identify a framework from which to inform their own strengths and weaknesses from which they felt confident to further develop their competency. For example;
"It enhances my clinical skills by guiding me to do the procedure in the correct order" (Student 2, 2020).

The clinical laboratories allow nursing students to practice learnt skills and consolidate practice in a "real-life" environment. The CSS was recognised as a tool that promoted the need for a higher proficiency in psychomotor skills and a resource to support this leading to safer delivery and quality of patient care.

\section{5) MAINTAINING TEACHING CONSISTENCY}

One of the key objectives of the CSS was to maintain teaching consistency. Nurse educators identified the CSS as helpful for maintaining teaching consistency among the teaching team. Some educators, especially those no longer working as clinicians, recognised the CSS as a helpful tool to maintain currency in clinical evidence-based practice. The feedback from educators included:

"The CSS provides an opportunity for an open discourse between tutors and students about inconsistencies they may have seen on videos or in clinical practice and allows them to critically reflect on principles, such as Aseptic Non-Touch Technique (ANTT), and improve their clinical coordination and skill level" (Educator 1, 2019).

Educators noted that the CSS assisted them in maintaining consistency in the delivery of the information and was specifically important for new educators:

"As a new tutor to the laboratory setting in 2018, implementing the Clinical Skills Storybook has allowed me to provide the same information and guidelines to all students from when I originally started teaching" (Educator 2, 2018).

Educators recognised the CSS supported student learning as:

"Students appear more competent and gained confidence very quickly than previous students" (Educator 3, 2020).

Overall, the result indicated that the CSS provided a uniform reference point to improve the learning experience in students and facilitate consistent teaching practices in educators. Embedding the CSS into the teaching practice for the nursing subject improved the teaching efficiency of educators in clinical skills laboratories. Furthermore, it fostered professional discussion about practice from which students could learn.

\section{6) STUDENT EVALUATION OF TEACHING (SET)}

Many factors influence students' perception of a subject. SET are a widely used metric by many educational providers to evaluate teacher effectiveness. Prior to implementing the CSS, these subjects SET in relation to teaching resources have been 
marked by several shortcomings. The student topic evaluations indicate satisfaction rates towards teaching resources with the CSS have improved significantly compared to the previous years (FIGURE 3)

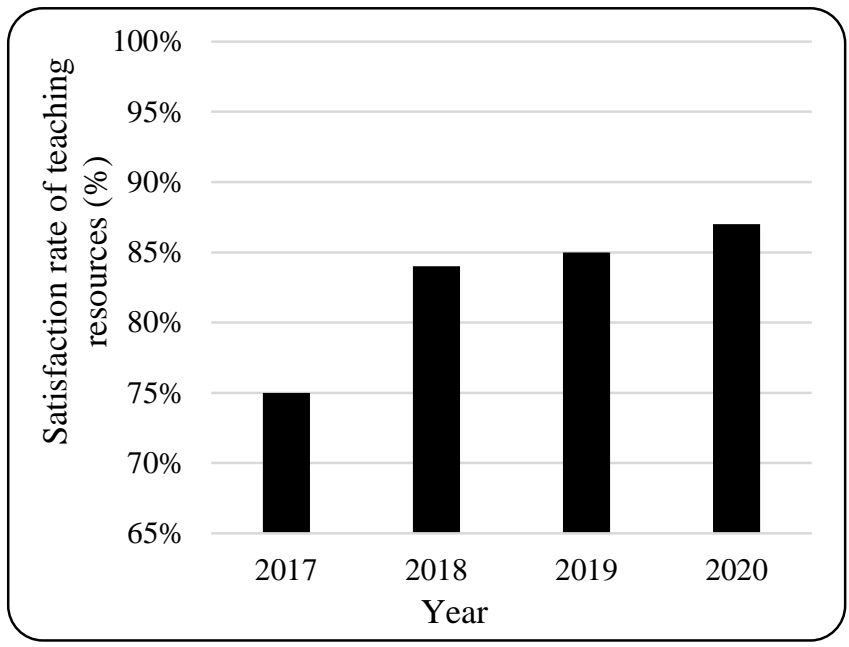

FIGURE 3. SET comparison 2017 -2020: Question: "These learning resources were of a high quality"

\section{DISCUSSION}

This study demonstrated that using the CSS was perceived by second-year undergraduate nursing students as valuable for developing psychomotor skills and identifying deficits related to clinical skill knowledge and delivery. Psychomotor skills are defined as skills that require coordination of sensory information and muscular response [14]. The acquisition of psychomotor skills requires repetitive practice [15]. Covid-19 pandemic has due restrictions on availability and social distancing [16]. Researchers clearly report using visual aids such as videos can help with skill acquisition and retention particularly during isolation [17, 18]. Quality videos are expensive and slow to produce, making it difficult to maintain accuracy with clinical updates. Saylers (2007) identified that students who were provided skill instruction before the class scored significantly higher in cognitive exams compared to traditional in-class teaching [19]. Picture based psychomotor skill teaching material such as the CSS can serve the same purpose evidenced by increased students' satisfaction, competence and confidence after the CSS implementation.

Furthermore, the CSS facilitated and encouraged self-directed learning and peer support among students. This study agrees with previous research that peer support is one of the factors that encourage students to practice and learn clinical skills [20]. A program that facilitates peer support also has increased students' satisfaction rates [21]. Peer support combined with repetitive practice had a significant effect on student skill development and retention of this knowledge [22]. Students are self-motivated in developing and improving their clinical skill competency as they recognise clinical skills as important to their future practice and public safety [23].

Psychomotor skill development is influenced by a range of aspects including availability of resources, role modelling and the educators' knowledge and ability to convey information $[5,20]$. Although there is no consensus of psychomotor skill teaching methods, most faculties have fundamentally used skill videos or in-class demonstration [24, 25]. However, limited space and time in the clinical laboratory, especially during the Covid-19 pandemic has led educators to consider alternative approaches to psychomotor skill acquisition. Students utilised CSS before and during the class as a skill demonstration, hence refocusing time and space from in class demonstration to hands on practice. In addition, the CSS served as an evidence-based resource among educators facilitating improved consistency in psychomotor skill teaching.

The implementation of the CSS in the clinical laboratory demonstrated several significant benefits. However, the limitations of this study could be addressed in future research. Firstly, the CSS was only implemented at one university in Australia. It may not be generalisable to other states or countries. Secondly, while the CSS assisted in ensuring consistency in the teaching approach of psychomotor skills, there is the potential that each educator may have different perspectives of teaching that may have impacted the results. A large teaching team often also leads to decreased equity in student experiences, which may mean that not all students had equitable exposure to the CSS resources. Thirdly, student perceptions are subjective, and the demonstrable benefit in learning outcomes is an important area for future research. The limitation of this study means a cautious approach should be taken when applying the results more generally.

\section{CONCLUSION}

This study aimed to evaluate the outcome of implementing the CSS as an additional teaching resource for undergraduate nursing students' clinical skill development. The acquisition of clinical skill proficiency is a gradual process, and the CSS can assist in a students' development in this area. This study identified that most students in this cohort welcomed the CSS as an additional and extremely valuable resource to assist them in developing confidence and competence in their psychomotor skills prior to clinical placement. Most students believed the CSS provided an easy-to-follow, visual guide that assisted in building their confidence and competence in clinical skills. Feedback from the educators working in the clinical laboratory and on placement was also very positive. This positive feedback has led to the expansion and further development of the CSS to include more skills, and the introduction of these CSS's into the third-year clinical subjects. Moving forward, the CSS's will now be introduced 
to all clinical subjects across the Bachelor of Nursing undergraduate program. To our best knowledge, there was no previous study that evaluated teaching resources using a sequential pictorial book to support undergraduate nursing student's psychomotor skill teaching and learning. This is especially valuable for any educational provider with limited resources as the CSS is cost effective to develop and easily updated to ensure evidence-based currency. An important area for future research is to establish a more demonstratable or quantifiable view of the CSS and seek support of the subjective view of students.

\section{REFERENCES}

[1] J. E. Lee and I. O. Sim, "Gap between college education and clinical practice: Experience of newly graduated nurses," Nursing Open, vol. 7, no. 1, pp. 449-456, 2020, doi: 10.1002/nop2.409.

[2] B. Donik, M. Pajnkihar, and M. Bernik, "Employability of Nursing Care Graduates," Organizacija, vol. 48, no. 4, pp. 287-297, 2015, doi: 10.1515/orga-2015-0023.

[3] H. Brendel and J. P. Walker, "Reconstructing a Nursing Skills Lab: A Quality Improvement Project," Nursing Education Perspectives, vol. 42, no. 6, pp. E120-E122, 2021.

[4] K. Illeris, Contemporary theories of learning: learning theorists... in their own words. Routledge, 2009.

[5] O. G. Mwale and R. Kalawa, "Factors affecting acquisition of psychomotor clinical skills by student nurses and midwives in CHAM Nursing Colleges in Malawi: A qualitative exploratory study," BMC Nursing, vol. 15, no. 30, pp. 1-9, 2016, doi: 10.1186/s12912-016-01537.

[6] Y.-H. Chuang, F.-C. Lai, C.-C. Chang, and H.-T. Wan, "Effects of a skill demonstration video delivered by smartphone on facilitating nursing students' skill competencies and self-confidence: A randomized controlled trial study," Nurse Educ Today, vol. 66, pp. 63-68, 2018, doi: 10.1016/j.nedt.2018.03.027.

[7] E. Lengetti et al., "An innovative approach to educating nurses to clinical competence: A randomized controlled trial," Nurse Educ Pract, vol. 33, pp. 159-163, 2018, doi: 10.1016/j.nepr.2018.08.007.

[8] H. Chan, M. Hassali, C. Lim, F. Saleem, and W. Tan, "Using pictograms to assist caregivers in liquid medication administration: a systematic review," Journal of clinical pharmacy and therapeutics, vol. 40, no. 3, pp. 266-272, 2015.

[9] B. Hill et al., "Automated pictographic illustration of discharge instructions with Glyph: impact on patient recall and satisfaction," Journal of the American Medical Informatics Association, vol. 23, no. 6, pp. 1136-1142, 2016.

[10] F. Aliakbari, N. Parvin, M. Heidari, and F. Haghani, "Learning theories application in nursing education," Journal of education and health promotion, vol. 4, 2015, doi: 10.4103/2277-9531.151867.

[11] S. Latimer, J. Hewitt, R. Stanbrough, and R. McAndrew, "Reducing medication errors: Teaching strategies that increase nursing students' awareness of medication errors and their prevention," ed: Elsevier, 2017.

[12] K. Shabani, M. Khatib, and S. Ebadi, "Vygotsky's zone of proximal development: Instructional implications and teachers' professional development," English language teaching, vol. 3, no. 4, pp. 237-248, 2010.

[13] M. Maguire and B. Delahunt, "Doing a thematic analysis: A practical, step-by-step guide for learning and teaching scholars," All Ireland Journal of Higher Education, vol. 9, no. 3, 2017.

[14] T. Changiz, Z. Amouzeshi, A. Najimi, and P. Adibi, "A narrative review of psychomotor abilities in medical sciences: Definition, categorization, tests, and training," Journal of Research in Medical Sciences, Review Article vol. 26, no. 1, pp. 69-69, January 1, 2021 2021, doi: 10.4103/jrms.JRMS_965_19.
[15] P. Benner, "Using the Dreyfus Model of Skill Acquisition to Describe and Interpret Skill Acquisition and Clinical Judgment in Nursing Practice and Education," Bulletin of Science, Technology \& Society, vol. 24, no. 3, pp. 188-199, 2004, doi: 10.1177/0270467604265061.

[16] M. D. Aldridge and E. McQuagge, "“Finding My Own Way": The lived experience of undergraduate nursing students learning psychomotor skills during COVID-19," Teaching and learning in nursing, vol. 16, no. 4, pp. 347-351, 2021, doi: 10.1016/j.teln.2021.07.002.

[17] J. de Lima Lopes, R. C. Negrão Baptista, C. Takao Lopes, M. Bertelli Rossi, E. A. Swanson, and A. L. Bottura Leite de Barros, "Efficacy of a video during bed bath simulation on improving the performance of psychomotor skills of nursing undergraduates: A randomized clinical trial," Int J Nurs Stud, vol. 99, pp. 103333-103333, 2019, doi: 10.1016/j.jijurstu.2019.04.001.

[18] D. L. Beskind et al., "Viewing a brief chest-compression-only CPR video improves bystander CPR performance and responsiveness in high school students: A cluster randomized trial," Resuscitation, vol. 104, pp. 28-33, 2016, doi: 10.1016/j.resuscitation.2016.03.022.

[19] V. L. Salyers, "Teaching Psychomotor Skills to Beginning Nursing Students Using a Web-Enhanced Approach: A Quasi-Experimental Study," Int J Nurs Educ Scholarsh, vol. 4, no. 1, pp. 11-12, 2007, doi: 10.2202/1548-923X.1373.

[20] M. D. Aldridge, "Nursing Students' Perceptions of Learning Psychomotor Skills: A Literature Review," Teaching and learning in nursing, vol. 12, no. 1, pp. 21-27, 2017, doi: 10.1016/j.teln.2016.09.002.

[21] M. Lee, H. M. Na, B. Kim, S. Y. Kim, J. Park, and J. Y. Choi, "Mediating effects of achievement emotions between peer support and learning satisfaction in graduate nursing students," Nurse Educ Pract, vol. 52, pp. 103003-103003, 2021, doi: 10.1016/j.nepr.2021.103003.

[22] J. G. Ross, "Repetitive Practice With Peer Mentoring to Foster Skill Competence and Retention in Baccalaureate Nursing Students," Nurs Educ Perspect, vol. 40, no. 1, pp. 48-49, 2019, doi: 10.1097/01.NEP.0000000000000358.

[23] R. M. Ryan and E. L. Deci, "Self-Determination Theory and the Facilitation of Intrinsic Motivation, Social Development, and WellBeing," The American psychologis, vol. 55, no. 1, pp. 68-78, 2000, doi: 10.1037/0003-066X.55.1.68.

[24] S. R. Kemery and B. L. M. Morrell, "Differences in Psychomotor Skills Teaching and Evaluation Practices in Undergraduate Nursing Programs," Nurs Educ Perspect, vol. 41, no. 2, pp. 83-87, Mar/Apr 2020, doi: 10.1097/01.NEP.0000000000000515.

[25] I. M. Saiboon et al., "Effectiveness of teaching automated external defibrillators use using a traditional classroom instruction versus selfinstruction video in non-critical care nurses," (in eng), Saudi medical journal, vol. 37, no. 4, pp. 429-35, Apr 2016, doi: 10.15537/smj.2016.4.14833 
Y.Yu is a registered nurse with more than 25 years full time acute care nursing experiences in China and Australia. Ying furthered her nursing qualifications since migrate to Australia in 2004 by completing a post graduate certificate in Intensive Care Nursing, a graduate certificate in Clinical Education and Master of Nursing. In 2018 Ying moved from

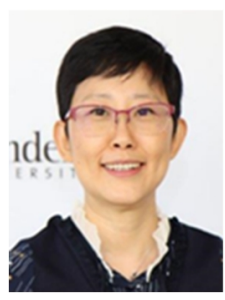
the clinical field to the academic field to share her knowledge and experience with the next generation of nurses. Ying excelled in her earlier academic career by receiving the Vice President \& Executive Dean's Education Award in 2019, Vice President's Teaching Excellence Award and Vice-Chancellor's Awards for Excellence in Teaching in 2020. Ying is completing her $\mathrm{PhD}$ at College of Nursing and Health Sciences, Flinders university, Australia with a scholarship funded by Medical Research Future Fund Australia. The field of study is online psychoeducation for informal caregivers of people living with dementia. Research interest include teaching and learning, cultural and linguistic diverse population, informal caregiver education and support. Recent publication: Yu, Y., Xiao, L., \& Chamberlain, D. J. (2021). Perceptions of care in patients from culturally and linguistically diverse background during acute and critical illness: A integrative literature review. Aust Crit Care, 34(5), 486-495. https://doi.org/10.1016/j.aucc.2020.11.004

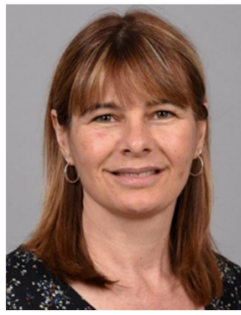

J. Price has a clinical background in Intensive care and Cardiac nursing, working in these areas for over 20 years. She completed Graduate Certificate in Health-Critical Care and Master of Nursing. She has extensive teaching experience, teaching at Flinders University since 2006, both as a casual and Full time Academic. She also worked as a Professional Placement Facilitator for Flinders University for 8 years. She teaches across the curriculum, however has a special focus on 3rd year Nursing students, working with them to assist them in gaining the knowledge and skills to ensure that they are successful Registered Nurses when they complete their degree. She is passionate about teaching and Nursing and has expertise working with students who require additional support in clinical skill and professional language development. Jodie is a Topic Coordinator, third year level Coordinator, Lab workforce Team leader, Nursing Communication and Practice Co-Project leader, Clinical Skill Storybook project and BN redesign team member.

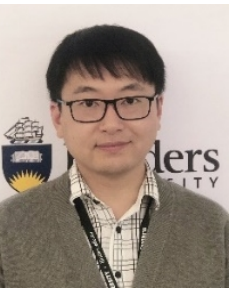

V. Pearson is a registered nurse at Royal Adelaide Hospital and an Associate Lecturer at Flinders University, South Australia. Vincent graduated with a Bachelor of Nursing and a Master of Nursing (Cardiac) from Flinders University. Currently, Vincent is pursuing postgraduate studies at Flinders University. His postgraduate research focuses on identifying a scalable implementation strategy for integrated atrial fibrillation care in primary care. Vincent has worked on multiple projects investigating cardiovascular health with researchers from Caring Futures Institute at Flinders University.

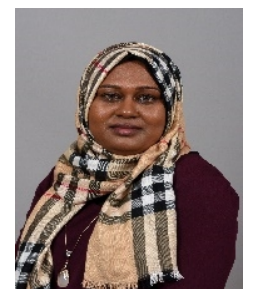

Dr FATHIMATH SHIFAZA Was born in the Maldives. She received her BSc of Nursing from Monash University, MSc from Adelaide University and $\mathrm{PhD}$ from the University of South Australia. Fathimath is a Senior Lecturer in Nursing at the College of Nursing and Health Sciences. Dr Shifaza is a registered nurse with additional qualifications in Midwifery and has over 20 years of clinical nursing and midwifery experience in Australia and Internationally. Her current research interest focuses on translating evidence to clinical practice, practice change and academic teaching styles. Fathimath's work underpins the importance of having Evidence-based Champions in a clinical setting to implement evidence-based practice. She has conducted several EBP research projects in clinical settings, academia. Her post-doctoral fellowship at the Ohio State University broadens her knowledge and scope of expertise in Evidence-based Practice. She frequently contributes to international conferences as a keynote speaker, invited speaker and acts as a peer reviewer for a number of International Journals. Dr Shifaza was a recipient of the College of Nursing and Health Sciences Teaching excellent Award 2021, Outstanding Health Researcher Award 2018 Ministry of Health, Maldives, the Endeavour executive fellowship in 2017- Department of Education and Training Australia, Australian Postgraduate Award 2011- Department of Education and Training -Australia.

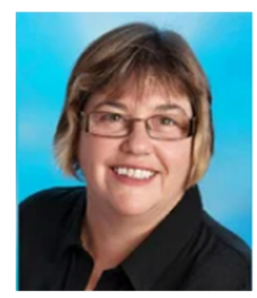

L. Pront is a registered nurse with a clinical background in rural/ remote emergency and theatre experience. Leeanne is a Nursing Lecturer at Flinders University with a passion for Clinical teaching and learning. As a $\mathrm{PhD}$ candidate her thesis focuses on the "what is good clinical supervision'. As the Placement Education Coordinator for Nursing at Flinders University her role supports ongoing development of clinical placement availability, education and support for clinical venues, clinical 
facilitators and student to optimise student learning in this environment.

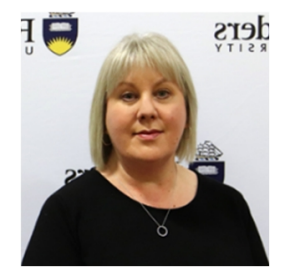

Ms Angie Sterland is a registered nurse and midwife working as the Senior Technical Officer (midwifery focus) in the simulation Healthcare Hub at College of Nursing and Health Sciences. Angie has additional qualifications in Graduate Certificate in Clinical Education and Diploma of Applied ScienceNursing. Angie's first nursing job was at the Adelaide Children's Hospital, specialising in infection control, respiratory and infectious disease management and later as the Clinical specialist for paediatric gastroenterology. Her nursing career has afforded her many diverse jobs and opportunities over the years with work interstate and in the community and disability sectors. Prior to commencing work at Flinders University Angie was the Unit Manager for a large Women's' Health Unit in a Northern Victorian hospital.In 2016 Angie returned to SA for family commitments and commenced her current role. Motivated by her new position and working closely with the academic team she has commenced a Masters degree of Clinical Education with a focus in simulation.Angie has a keen interest in simulation and its impact on learning and teaching and believes that the greatest reward from this role is to observe a student deeply engaged in their learning in an authentic simulated activity. 